\title{
Iluminismo pedagógico e educação natural em Jean-Jacques Rousseau
}

\author{
Cristiano Eduardo Wendt* \\ Claudio Almir Dalbosco**
}

\section{Resumo}

O ensaio discute a importância de Jean-Jacques Rousseau para a pedagogia moderna, tendo por base sua obra filosófico-pedagógica Emílio ou da Educação. Este texto busca apresentar qual o significado do lluminismo pedagógico, bem como a concepção de educação natural, e as duas grandes novidades trazidas por Rousseau para o campo educacional, a saber, os conceitos de infância e de educação. Nesta perspectiva, analisa as três principais interpretações a que o lluminismo rousseauniano foi submetido ao longo da história: como otimista da razão, primitivista e dialético da razão. Assumindo o pensamento do genebrino como defensor de uma dialética da razão, o ensaio procura refletir sobre os desdobramentos que esta concepção provoca ao seu projeto de educação natural e como reflete no desenvolvimento cognitivo e moral dos infantes. Por fim trata de apresentar duas inovações que Rousseau traz para o campo da educação, a primeira no que diz respeito ao conceito de infância e, a segunda, ao processo pedagógico como um todo, considerando as fases de amadurecimento biológico, cognitivo e moral, nas quais cada criança se encontra.

Palavras-chave: pedagogia, educação natural, lluminismo, dialética da razão.

\section{Pedagical enlightenment and natural education in Jean-Jacques Rousseau}

\section{Abstract}

The essay discusses the importance of Jean-Jacques Rousseau for modern pedagogy, by being grounded on his philosophical-pedagogical work Émile or On Education. It seeks to present the meaning of pedagogical enlightenment as well as the concept of natural education, and the two great novelties brought by Rousseau to the educational realm, i.e., the concept of infancy and of education. In this perspective, it analyzes the three main interpretations to which Rousseau's enlightenment was submitted along history: As an optimist of reason, primitivist and dialectician of reason. Assuming the Genevan's thought as a defender of a dialectics of reason, the essay seeks to reflect the unfolding which every concept

\footnotetext{
* Professor temporário do Instituto Federal de Educação, Ciência e Tecnologia do Rio Grande do Sul - Campus Ibirubá (IFRS). Ibirubá, Rio Grande do Sul, Brasil.

${ }^{* *}$ Professor Doutor titular da Universidade de Passo Fundo, Bolsista de Produtividade em Pesquisa do CNPq - nível 2. Passo Fundo, Rio Grande do Sul, Brasil.
} 
provokes to its project of natural education and how it reflects in the cognitive and moral development of the infants. At last it deals with the presentation of two innovations which Rousseau brings to the realm of education, the first one which deals with the concept of infancy, and the second one which deals with the pedagogical concept as a whole, by considering the phases of biological, cognitive and moral maturing, where each child is encountered.

Keywords: pedagogy, natural education, enlightenment, dialectics of reason.

\section{Considerações preliminares}

A pedagogia moderna é tributária, em grande parte, do pensamento de Jean-Jacques Rousseau, o qual se encontra esboçado em sua obra filosófico-pedagógica Emílio ou da Educação. Nela podemos visualizar o quanto o filósofo suíço contrapõe-se criticamente às ideias de seu tempo, seja às que defendiam o modelo de educação escolástico ou, ainda, àquelas que acreditavam na razão como único meio para evolução da humanidade. Esta última, considerada a bandeira do movimento iluminista. Sabe-se que o Emílio foi escrito ao mesmo passo que o Contrato Social, fato este que faz com que as duas obras se complementem no que se refere a um modelo de educação-formação dos sujeitos. As duas obras estão sustentadas pelo pensamento pedagógico de fundo que busca a formação de homens capazes de lutarem contra a depravação da natureza humana, aptos a ouvirem a própria voz de sua consciência. Ou seja, como um autêntico pensador moderno, Rousseau vê na interioridade humana, cuja consciência é o núcleo de sua autenticidade, a força motriz capaz de fazer frente à corrupção humana resultante da socialização distorcida (TAYLOR, 1997, p. 455-470).

Sobre as críticas tecidas pelo genebrino ao ideal iluminista tem-se como primeira e fundamental o poder exagerado atribuído à razão, o que conduz à interpretação daquilo que é próprio do lluminismo rousseauniano, no que ele se aproxima ou se distancia dos pensadores de sua época. Para tanto, nos cabe, neste momento, uma tentativa de identificar qual o lluminismo defendido por Rousseau e como se articula com seu projeto pedagógico. Serão consideradas aqui as interpretações que o definem como otimista da razão, como primitivista ou, ainda, como um dialético da razão.

Dos desdobramentos daquilo que pode ser compreendido como 0 lluminismo rousseauniano somos levados à tentativa de evidenciar as implicações acarretadas na proposta pedagógica do genebrino. Com isso queremos adentrar naquilo que denominamos como lluminismo pedagógico rousseauniano. Dentro desta temática somos conduzidos a explorar e trazer indicativos do projeto de educação natural empreendido no Emílio: como concebe a ideia de educação e qual o papel da natureza dentro desta perspectiva? De antemão preci- 
samos esclarecer que uma resposta a essa pergunta não é uma tarefa fácil porque encontramos dificuldades tanto referentes ao estilo pouco sistemático do autor como à própria complexidade do assunto, pois saber o que é natureza e como Rousseau a conecta com a educação, colocando-a em sua base é uma pergunta que já demandou inúmeras pesquisas sem que se pudesse chegar até hoje a um bom termo. ${ }^{1}$

Sabe-se que as duas grandes novidades trazidas pelo Emílio dizem respeito, primeiramente, à crítica ao modelo escolástico (tradicional) de educação, o qual se fundamenta num verticalismo e intelectualismo pedagógico, não vendo na criança o sujeito do processo pedagógico e, a segunda, à ressignificação do conceito de infância.

Em síntese, movidos pelo problema da conexão entre educação e natureza, vamos tecer, em primeiro lugar, algumas considerações gerais sobre a noção de lluminismo assumido por Rousseau. Na sequência, buscamos abordar o vínculo entre seu lluminismo pedagógico e sua ideia de educação natural. Por fim, no último tópico do ensaio, trataremos da noção de infância que resulta de seu lluminismo pedagógico, o qual vem alicerçado na noção de educação natural.

\section{O lluminismo rousseauniano}

São os inúmeros paradoxos e peculiaridades presentes na vida e no pensamento de Rousseau que talvez nos auxiliam a ver melhor sua singularidade e contribuição ao projeto iluminista ${ }^{2}$ de sua época. Deste modo, Rousseau não pode ser visto nem como um iluminista tout court, ou seja, como um entusiasta ingênuo em relação ao poder emancipador da razão, nem como seu crítico radical, que ao defender a teoria do bom selvagem teria negado por completo as potencialidades inerentes à racionalidade humana.

Para dar vazão a esta linha de investigação, tomaremos três interpretações acerca do seu pensamento. Cada um delas possibilitará, ao seu modo, que o situemos dentro do contexto iluminista que marcou o século XVIII: a) Rousseau como um otimista no que se refere aos rumos da civilização; b) Rousseau como um primitivista; e, c) Rousseau como um dialético da razão (DALBOSCO, 2011, p. 113-137).

A primeira coloca o suíço como um crente no ideal emancipador da razão humana, ou seja, um Rousseau que aderira a teoria otimista do progresso humano e social. Um pensador que poderia ser resumido na afirmação de que a razão humana, juntamente com a ciência moderna, levaria os homens à felicidade. Se esta interpretação fosse condizente com seu pensamento como um todo, teríamos um filósofo puramente racionalista. Entretanto, se assumíssemos isto como verdade deveríamos fazer vistas grossas para duas questões que nos impossibilitariam de prosseguir nesta direção. A primeira delas trata de 
que o próprio movimento iluminista não se erguia em univocidade para defender seus ideais. Assim sendo, o próprio Rousseau, como os demais expoentes deste período, não pode ser compreendido como um intelectual ingênuo ao ponto de tomar como certa e infalível a afirmação esboçada. Outro ponto decorrente deste é que o próprio genebrino não permite em seus escritos que seja tomado como um defensor do progresso humano. Pelo contrário, para o genebrino o progresso das ciências e das artes não significava o melhoramento moral da humanidade, mas sim a sua depravação. Esta abordagem nos conduz a abandonar uma concepção simplista e caricaturada do lluminismo, bem como de um Rousseau crente no potencial emancipador da razão humana e no poder da ciência.

A segunda interpretação concebe Rousseau como primitivista. Essa concepção toma força com a interpretação errônea de sua obra, cuja origem se encontra em Voltaire, que interpreta o pensamento do genebrino como uma defesa da teoria do bom selvagem, isto é, teoria que afirma que para o homem ser feliz deveria abandonar a civilização, a vida em cidade e retornar à floresta. Esta ideia por si só é totalmente oposta ao Rousseau otimista da razão e contrária ao que realmente pensa o genebrino. Porém, ela toma forma para sustentar sua defesa nas críticas à sociedade europeia de sua época, ao luxo e artificialismo das relações, ou ainda como Rousseau mesmo conceitua, aos coquetismos sociais que são os mediadores das relações entre os cidadãos. É exatamente contra esse tipo de relação que ele pensa uma vida distante dos grandes salões, e das luzes da ribalta, buscando na simplicidade do campo a proximidade do homem com aquilo que é próprio de sua natureza, ou seja, sua interioridade. É via progresso social e econômico que os homens são coagidos a tornarem-se corruptos e maldosos. O que deve ser salientado neste ponto é que Rousseau não prega um abandono de tudo que já fora conquistado pela cultura e ciência, tão pouco um retorno à vida primitiva. O que busca é empreender questionamentos acerca dos caminhos que estão sendo trilhados pela civilização ocidental, a qual abusa de determinados procedimentos racionais e do desenvolvimento técnico-científico, em prol da satisfação de seus caprichos e de uma vida baseada na artificialidade e no mundo do "parecer ser".

Chegamos ao terceiro ponto desta discussão, à interpretação de Rousseau como dialético da razão. O que a ideia de dialética procura neste contexto é apontar para a não existência de um único e engessado modelo de racionalidade que possa ser seguido como norte. Assim, não há apenas uma interpretação dos fatos, assim a razão deve estar em permanente processo de reflexão sobre si mesma, evitando tomar como absoluto este ou aquele modo de explicar a história. No que se refere ao pensamento do genebrino, a dialética representa a capacidade humana de aprender a pensar de forma paradoxal. $\mathrm{Ou}$ seja, a capacidade dos homens em refletir sobre as tensões existentes em suas vidas e a busca em resolver ou contornar da melhor maneira possível tais problemas. O que deve ser ressaltado, segundo esta interpretação, é a busca em conceber o ser humano como um ser que, além de sua capacidade racional 
reflexiva, também é constituído por sentimentos, paixões e afetos. Isso nos remete diretamente a teoria moral de Rousseau, visto que o sentimento para ele está diretamente ligado à consciência.

No dizer de Dalbosco (2011, p. 124):

Dialética da razão exprime, nesse sentido, a compreensão adequada da tensão imanente à ação humana que se manifesta entre as dimensões da consciência (enquanto instinto humano e "divino") e da razão, ambas inseridas em uma ordem universal. Ela consiste enfim no movimento crítico que se inicia com o "cuidado de si mesmo", o qual, por sua vez, conduz à consciência da inserção humana no cosmo.

Além do conteúdo desta passagem, há ainda outro aspecto a se considerar. Para compreender de forma mais sistemática esse ideia de dialética no pensamento de Rousseau, deve-se buscar amparo na tensão existente entre o "ouvir a voz do coração" e o "seguir os ditames da razão". Neste horizonte, ser racional não significa agir só logicamente com base em conceitos, muito menos através de ações procedimentais baseadas em relações instrumentais de meiofim. O que retrata a dialética é a busca por formulação de juízos que sofram a influência da voz do coração e dos sentimentos que constituem o psiquismo humano. Esta seria, a nosso ver, a interpretação que mais se aproxima do pensamento rousseauniano e de modo especial ao seu projeto de educação natural.

Neste contexto, recorremos ao pensamento de Cassirer para buscar subsídios que possibilitem avançar nesta temática. Segundo ele, devemos considerar, na "teoria" ou "dinâmica do sentimento" proposta por Rousseau, duas tendências que são completamente opostas, descritas como ora idealista ora naturalista (CASSIRER, 1999). Para conectarmos essa ideia com sua teoria moral, podemos indicar, pelo viés naturalista, que o sentimento é originado das sensações e causa as impressões. No que tange o viés idealista, existe uma região da consciência que não pode ser acessada pela mera sensação, sendo alcançada pelo caminho do julgamento. Posto isso, e se realmente esta segunda interpretação é parte do pensamento de Rousseau, temos então um problema, a saber, como se conecta sentimento e julgamento? Retomando as ideias de Cassirer (1999), pode-se inferir que ele o faz distinguindo o que é sentimento, por um lado, daquilo que é mera sensação e, por outro, das operações lógicas do entendimento. Em síntese, podemos dizer que aquilo que o genebrino compreende por julgamento não se limita à fundamentação das operações lógicas efetuadas pelo entendimento, sendo necessário incluir, neste contexto, no que se refere à moralidade, o recurso à "voz da consciência".

O que se tentou apresentar neste terceiro ponto trata de mostrar que há o fechamento do "círculo da teoria do sentimento de Rousseau, pois o senti- 
mento ergue-se agora bem acima da 'impressão' passiva e da mera sensação; ele assimilou a pura atividade do julgamento, da avaliação e da tomada de posição" (CASSIRER, 1999, p. 107). Assim, evitando o reducionismo ao "instinto primitivo" ou ainda "as regras lógicas do entendimento", pode-se dizer que o sentimento tem sua manifestação causada ora como uma afecção psíquica ora como algo essencial da alma, isto constitui a própria dialética da razão, tomada no seu sentido mais amplo. Portanto, e este é o ponto fundamental que nos interessa aqui, vinculada ao sentimento, sendo sua própria expressão, trata-se agora de uma razão que não se deixa mais reduzir aos seus procedimentos meramente lógico-formais, mas sim, que ao pensar sente e que só pode pensar exatamente porque é sensível.

Esta característica dialética rompe com a interpretação de um Rousseau otimista da razão, pois em seu pensamento de modo mais pontual no Primeiro e Segundo Discursos ele aponta para que os avanços obtidos, seja pela cultura ou pela arte, fundamentados numa relação técnico-instrumental, não necessariamente conduzem os indivíduos à emancipação proposta pelas luzes. Podem levar sim à depravação moral, pois conduzem os sujeitos a um fechamento em si mesmos, compreendendo os outros não como pares de um processo de melhoramento da civilização, mas sim como objetos a serem utilizados em benefício próprio.

Também temos que apontar para a superação da interpretação de um Rousseau primitivista, pois não se pode aceitar o retorno à natureza como um retrocesso no modo de vida, como já foi exposto, indicando que os sujeitos deveriam retornar ao hábitat natural em meio às matas virgens. Ou, ainda, como coloca Voltaire em sua crítica à Rousseau, de vivermos novamente sob quatro patas. O que se busca deste "voltar à natureza" é sim que os homens possam escutar a voz de sua consciência, somente ouvida por meio do processo de voltar-se a seu interior, aquilo que o constitui propriamente enquanto ser capaz de definir por si próprio o que é o bem.

\section{Iluminismo pedagógico e educação natural em Rousseau}

Para fins pedagógicos recorremos ao Livro IV do Emílio, onde o autor apresenta a tensão existente entre o amor de si e o amor-próprio. Esta tensão tem como fundamento a preparação moral dos sujeitos, pois coloca frente a frente os desejos que pertencem à esfera da satisfação das necessidades, em que o único envolvido é o próprio sujeito, e a comparação com os outros, na qual preferimos sempre a nós mesmos. $\mathrm{O}$ amor de si mesmo refere-se às paixões doces e afetuosas; já o amor-próprio, às paixões odientas e irascíveis. E é com base neste confronto que o indivíduo deve dar ouvidos à sua interioridade, à voz de sua consciência.

Para adentrarmos mais pontualmente no projeto de educação natural dentro do contexto iluminista, apresentando alguns aspectos iluministas em 
seu projeto educacional, vamos rapidamente pontuar alguns indicativos do que é o natural para Rousseau.

Sabemos que, em muitos momentos da história da pedagogia, posteriores à publicação do Emílio, a natureza é tomada na perspectiva romântica adotada pelo século XIX, no sentido de que tudo aquilo que é natural está em oposição ao que é social (artificial). Ou seja, procurava-se demonstrar a autenticidade, que não fora ainda contaminada pelas relações sociais. Para os românticos, o contraponto entre natureza e sociedade civilizada pode ser entendido, resumidamente, no sentido de que quanto mais sociável o ser humano se torna mais ele se distancia do conceito de natureza e, com ela, da bondade que constitui originariamente todo ser humano. Em não raras ocasiões se atribuiu a Rousseau um projeto educacional que procura educar os infantes longe da vida em sociedade. Porém, em uma leitura atenta de sua obra percebe-se que o natural da educação possui uma relação estreita com a sociedade, compreendendo esta no seu sentido normativo.

Tratar do conceito de educação natural e de natureza neste autor é de fundamental importância para que possamos, mais consistentemente, compreender os objetivos do seu projeto educacional. A teoria educacional rousseauniana pode ser dividida em dois momentos: o primeiro trata da educação na infância e o segundo da educação na adolescência e juventude. Esses dois momentos se apresentam no Emílio, nos Livros I e II, respectivamente. O Livro I faz referência à atenção para com os cuidados e as necessidades da criança, período que compreende de zero até os dois anos de idade. O Livro II, por sua vez, trata da idade dos dois aos doze anos, na qual o problema nuclear é a inserção do projeto de educação natural dentro de uma visão cosmológica de maior amplitude. Um projeto pedagógico como esse não poderia se ausentar de investigar a relação pedagógica entre a criança e o adulto, tendo, nesse caso, como foco a educação pelos sentidos, ${ }^{3}$ tomada no horizonte da ideia de força e do refinamento dos sentidos e, claro, como se apresenta na obra do genebrino, a necessidade de se educar para a moral, para a entrada de Emílio na sociedade.

Segundo comenta Dalbosco, "o homem só pode tornar-se um ser moral quando ingressa na sociedade, porém, ao ingressar nela, corre o risco constante de se 'extraviar"' (DALBOSCO, 2005, p. 80). Enfim, podemos dizer que a moralidade tem sua base na sociabilidade. Assim, a educação de Emílio deveria prezar desde cedo, ou seja, "desde sua primeira infância, para conhecer e desenvolver suas potencialidades, aprendendo a obedecer aos limites postos pelo meio sócio-histórico que o circunda" (DALBOSCO, 2008, p. 139). Prossegue Dalbosco, dizendo que nesta "aprendizagem de infância, a natureza é a grande professora e o adulto (educador) é o mediador entre ela e o educando" (2008, p. 139). O problema que se apresenta na ideia de ter a natureza como principal professora refere-se à situação entre o deixar acontecer e o intervir no mundo do infante. Rousseau coloca que devemos deixar "a natureza agir bastante tempo antes de resolver agir em seu lugar, temendo contrariar suas operações” (ROUSSEAU, 2004, p. 119). 


\section{Cristiano Eduardo Wendt - Claudio Almir Dalbosco}

A questão importante dos Livros I e II versa acerca do projeto de educação natural, uma educação voltada para a primeira infância, tomando as necessidades da criança e os cuidados que o adulto exerce sobre ela. O que cabe ressaltar aqui é a importância que deve ser atribuída ao amadurecimento dos infantes; as necessidades da criança e os cuidados do adulto, que devem se modificar de acordo com o amadurecimento dos primeiros. E é de fundamental prioridade que $o$ adulto consiga visualizar e mediar a tensão entre o que realmente é necessidade e o que ele deve dispensar a ela enquanto cuidado. $\mathrm{Ou}$ seja, deve o adulto tomar todas as precauções para que seus cuidados não venham a viciar a criança. Assim, a ação do adulto deve ser de reconhecer o que é natural na criança, distinguindo a necessidade verdadeira daquela que é fantasiosa.

Rousseau expressa este problema da seguinte maneira:

Há um excesso de rigor e um excesso de indulgência, ambos a serem igualmente evitados. Se deixas a criança sofrer, pondes em risco a sua saúde, na sua vida; vos a tornais desde logo miserável; se Ihe poupais com demasiado cuidado toda espécie de mal-estar, preparaisIhe grandes misérias; vos a tornais delicada, sensível; vos a tirais do seu estado de homem, a que voltara. (1992, p. 70)

O que cabe ressaltar, e isso aparece nas linhas do Livro II, é a ideia de humanismo, ou seja, a educação natural tem como meta o humanismo. Mas, como Rousseau opera com essa ideia de humanismo na infância? Poderíamos dizer que é a busca por deixar a criança ser o que ela é. Assim, natural é saber qual é o seu lugar num sentido ético normativo bem claro, na relação entre as necessidades, os desejos e as forças disponíveis para atender as necessidades. Ao descobrir o seu lugar na ordem das coisas, a criança cria um sentimento de pertença que Ihe é fundamental para não ultrapassar os limites no seu futuro convívio social. Pode-se, então, afirmar que natural é o equilíbrio entre desejo e o poder de alcançar o desejado, respeitando-se a si mesmo e aos outros.

Tomando o conceito de educação natural esboçado no Emílio, Rousseau procura apontar que ela é a fonte de formação do caráter dos infantes. Apontamos, a partir do esboçado, para a possível tese de que a finalidade maior do projeto educacional rousseauniano, nos Livros I e II, é auxiliar na condução da criança, através da educação natural, a ser um sujeito autônomo, capaz de pensar por conta própria, possibilitando-a viver livremente, em um governo republicano, quando adulto.

Em síntese, o projeto de educação natural pensado por Rousseau à criança de zero até doze anos de idade deve respeitar a criança naquilo que ela é tanto do ponto de vista biológico, como afetivo e cognitivo, primando mais pelo 
amadurecimento de suas forças físicas e sensíveis, expondo-a ao convívio direto e permanente com a natureza. O genebrino era da convicção pedagógica de que o fortalecimento do corpo e o refinamento dos sentidos seriam a condição necessária, embora não suficiente, do posterior e progressivo desenvolvimento cognitivo e moral da criança.

\section{A invenção moderna dos conceitos de infância e pedagogia}

Uma única obra sobre educação transforma a trajetória de Rousseau no Emílio ou da Educação, apresentando uma gama de possibilidades e novidades para se pensar a educação e o processo de desenvolvimento dos educandos. Esta obra filosófico-pedagógica que faz com que seu autor esteja entre os mais importantes pensadores de todos os tempos, já foi motivo de perseguição e o alimento para fogueiras que acalentavam o ego dos doutos racionalistas e os soberanos teólogos e religiosos.

Rousseau, ao longo das páginas do Emílio, nos apresenta duas grandes mudanças em relação aos processos pedagógicos de seu tempo. A primeira é exatamente sobre a ideia de educação, contrariando toda a tradição escolástica. A segunda é a reinvenção do conceito de infância. Destas surgem inúmeros desdobramentos que, no seu conjunto, demonstram porque obra e autor são o divisor de águas do pensamento pedagógico moderno.

Adentrando na seara de discussão das objeções rousseaunianas acerca do modelo de educação escolástico e do ideal de infância, temos como principal objeto de crítica o intelectualismo pedagógico que dominava até então. O genebrino procurava mostrar em sua obra que não devemos conceber a criança como um adulto em miniatura, concepção que acarreta diretamente a impossibilidade de se iniciar a educação pela razão.

Trocando em miúdos, e este é o objeto dos Livros I e II do Emílio, devemos antes de tudo fortalecer o corpo e refinar os sentidos dos infantes, para que possam ir aos poucos desbravando o mundo que os circunda, isto é, o que se denomina educação pelas coisas. Entende-se que a razão não deve estar no início do processo educativo, tal ideia vem na contramão daquilo que pensavam muitos autores de seu tempo, entre eles Locke. Segundo o próprio Rousseau: "De todas as faculdades do homem, a razão, que não é por assim dizer, senão um composto de todas as outras, é a que se desenvolve com mais dificuldade e mais tardiamente, e é ela que se pretende utilizar para desenvolver as primeiras!" (ROUSSEAU, 2004, p. 89).

Se recordarmos a proposta da educação tradicional, o aluno não era considerado sujeito no processo pedagógico, mas tido sim como receptáculo de informações, que lhe eram transmitidas de forma meramente verbal, sem o recurso ao jogo e à brincadeira. Assim, os conteúdos se faziam distantes do universo infantil, dificultando a compreensão e aplicabilidade. A ideia de criança 
como adulto em miniatura impede que ela viva aquilo que é próprio de seu tempo, de sua idade, pois deve vestir-se e portar-se como um adulto, ficando sujeita à corrupção e aos coquetismos que são próprios do mundo adulto. Com isso fica impossibilitada de viver aquilo que é próprio de sua fase, ou seja, a alegria e a espontaneidade da infância.

A educação natural proposta por Rousseau busca respeitar o infante em seu mundo; isto por si só demonstra a ruptura clara com os alicerces da pedagogia tradicional reinante. O ideal de criança combatido por Rousseau está fortemente atrelado ao conceito de inatismo presente na filosofia platônica e que perdurou por toda a Idade Média. Se recorrermos à filosofia verificaremos no Menão de Platão a justificativa que baseava o conhecimento na teoria das ideias, a qual apresenta, grosso modo, a distinção entre o mundo sensível e o mundo inteligível. O primeiro é depositário de tudo que é considerado imperfeito, contraponteando desta maneira o mundo inteligível que é a fonte de tudo que é bom e puro, daquilo que é perfeito.

Assim, a criança, ao passo que fosse sendo racionalmente educada, estaria de uma forma ou outra acessando todo o conhecimento que nela estaria adormecido. Isso deu margem à toda tradição escolástica defender e sustentar seu verticalismo e intelectualismo pedagógico, os quais impossibilitavam compreender o aluno como sujeito no processo educativo. Todo o inatismo presente neste modelo escolástico foi ponto de partido para Rousseau dar forma ao Emílio. Neste horizonte é que o genebrino pensa a importância do meio e do professor no processo de educação de Emílio. O primeiro com o papel de ofertar ao seu aluno a experiência, o contato, com tudo que o circunda. $O$ segundo, como mediador da relação da criança com aquilo que vai descobrindo. Dessa forma, evita-se que coloque sua vida em risco ou ainda que faça algo além de suas forças.

Em forma de conclusão, podemos dizer que, ao justificar o princípio básico da educação natural de respeito ao mundo da criança, isto é, de respeito a sua condição biológica, cognitiva e intelectual, nas quais a criança se encontra, Rousseau antecipa, ao seu próprio modo e estilo, um pilar da pedagogia contemporânea, qual seja, o de tomar as potencialidades da criança, considerando suas capacidades e o seu modo de ação, como ponto de partida do processo pedagógico. Como a criança aprende interagindo com o meio, moldando seu comportamento através do processo tensional de ação e reação junto aos objetos físicos e aos traços culturais e sociais que lhe vêm ao seu encontro, é de fundamental importância que o educador conheça suas potencialidades e seus limites, exatamente na fase em que o educando se encontra, e, mais do que isso, seja capaz de criar o ambiente pedagógico necessário para mobilizar o desenvolvimento biológico, humano e social de seu educando, ao mesmo tempo em que, ao fazer isso, estará construindo a si mesmo como ser humano. 


\section{Referências}

BENNER, D.; BRÜGGEN, F. Geschichte der Pädagogik. Vom Beginn der Neuzeit bis zur Gegenwart. Stuttugart: Reclam, 2011.

CASSIRER, E. A questão Jean-Jacques Rousseau. São Paulo: Editora Unesp, 1999.

COOPER, L. D. Rousseau, Nature, the Problem of the good Life. Pennsylvania: The Pennsylvania State University, 1999.

DALBOSCO, C. A. Educação natural em Rousseau. Das necessidades da criança e dos cuidados do adulto. São Paulo: Cortez Editora, 2011.

. Teoria social, antropologia filosófica e educação natural em Rousseau. In: DALBOSCO, C. A. FLIKINGER, H. G. (Org.). Educação e maioridade: dimensões da racionalidade pedagógica. São Paulo: Cortez Editora; Passo Fundo: UPF Editora, 2005. p. 70-103.

Crítica da razão e iluminismo pedagógico em Rousseau. In: SGRÓ, Margarita. Teoría Crítica de la Sociedad, Educación, Democracia y Ciudadanía. Tandil: UNCPBA, 2008. p. 121 - 144.

ROUSSEAU, J. J. Emílio ou da Educação. Rio de Janeiro: Bertrand Brasil S.A. 1992.

. Emílio ou da Educação. São Paulo: Martins Fontes, 2004.

SCHNEIDERS, W. Das Zeitalter der Aufklärung. München: Verlag C. H. Beck, 2008.

TAYLOR, C. As fontes do Self. A construção da identidade moderna. São Paulo: Edições Loyola, 1997.

\footnotetext{
Notas

1 O conceito rousseauniano de natureza, assim como o de educação, reúne muitas dificuldades. Dentre a extensa literatura sobre o tema, destacamos o estudo mais recente de Cooper (1999). $\mathrm{Na}$ introdução de seu estudo, o referido autor critica tanto a concepção "historicista" como transcendental de natureza para afirmar sua própria posição (p. 4-11).

${ }^{2}$ Considerando a amplitude e complexidade do movimento iluminista que dominou a Europa nos séculos XVII e, sobretudo, XVIII, foge de nossa alçada caracterizá-lo em detalhes. Para o que nos interessa no momento, basta defini-lo como uma forma de pensamento que acredita no poder emancipador tanto da razão como da ciência, baseando-se numa perspectiva otimista da história humana, ou seja, na crença de que pela razão e pela ciência o homem seria capaz de resolver todos seus problemas. Para um resumo atual e bem fundamentado da época do lluminismo, ver o estudo introdutório de Schneiders (2008).

${ }^{3}$ Ao defender que a educação infantil deve iniciar pela educação dos sentidos, Rousseau inova em relação à tradição pedagógica, sobretudo em relação ao racionalismo escolástico, segundo o qual a criança deveria ser educada desde seu início pela razão. Contudo, o pensamento pedagógico de Rousseau ainda é tributário, no geral, da noção clássica de educação que a concebe como uma ordem progressiva, contemplando diferentes etapas: a) formação dos
} 


\section{Cristiano Eduardo Wendt - Claudio Almir Dalbosco}

sentidos; b) da linguagem e da memória; c) do aprendizado imitador da ordem da natureza (kosmos) e; d) por fim, do aprendizado e convívio com a comunidade pública (polis). Sobre esse traço clássico da educação antiga que influenciou diretamente o humanismo renascentista e a pedagogia iluminista moderna, ver os dois primeiros capítulos da brilhante história da pedagogia escrita por Benner e Brüggen, publicada recentemente (2011, p. 11-50).

\section{Correspondência}

Cristiano Eduardo Wendt - Avenida Júlio de Castilhos, 2767, Bairro Expedicionário, CEP 99300-000, Soledade, Rio Grande do Sul.

E-mail: wendt81@hotmail.com - vcdalbosco@hotmail.com

Recebido em 24 de fevereiro de 2012

Aprovado em 24 de março de 2012 